\title{
Urban CDEPs as Indigenous Employment Centres: Policy and community implications
}

\section{Champion}

No. 228/2002

ISSN 1036-1774

ISBN 0731556038

Mark Champion is an Indigenous Visiting Fellow at the Centre for Aboriginal Economic Policy Research, The Australian National University, on an inter-agency placement from the Aboriginal and Torres Strait Islander Commission's Regional Office in Queanbeyan, New South Wales. 



\section{Foreword}

This Discussion Paper on the Community Development Employment Projects (CDEP) scheme in the Sydney metropolitan region and on the early implementation of a program to use existing urban CDEP organisations as Indigenous Employment Centres (IECs) was not foreshadowed in the CAEPR Research Plan of 2001. The Centre had undertaken considerable research on the CDEP Scheme in 2000, culminating in the November conference The Indigenous Welfare Economy and the CDEP Scheme and the publication in 2001 of a CAEPR Monograph with the same title, edited by Frances Morphy and Will Sanders.

The research reported in this Discussion Paper originated in the coincidence of two events. First, in May 2001, the federal Budget carried the announcement of a new policy framework-Australians Working Together (AWT)-that was the government's response to the McClure Reference Group Report on Welfare Reform completed in 2000. An important change in policy direction was put forward: an enhanced emphasis on mainstream employment outcomes from CDEP scheme participation, especially in situations where viable labour markets are deemed to exist. An important element of this change in emphasis was the establishment of IECs. The early stages of this initiative are the focus of this paper.

Another plank of this new framework focused on situations in regional and remote Australia where viable labour markets are non-existent or are heavily circumscribed. In such situations a new option, Community Participation Agreements, was introduced. This development was discussed in some detail in Diane Smith's 'Community Participation Agreements: A model for welfare reform from community-based research' (CAEPR Discussion Paper 223, 2001). That Discussion Paper and the present one together provide some early analysis of the AWT initiatives in urban and remote contexts.

The second event that led to this Discussion Paper was the inter-agency placement of Mark Champion, an Indigenous project officer for ATSIC's Queanbeyan Regional Office, at CAEPR from April 2001. Mark is the second ATSIC officer to undertake a placement, initially for six months and then extended to one year. This paper is being published just as Mark is completing his secondment. This research was Mark's idea from the outset and during his time at CAEPR he has not only produced this paper, but also made a number of presentations on its subject matter, most recently in Alice Springs in December 2001. This research attests to Mark's commitment and to his skill as a researcher, particularly as someone who has come to CAEPR with no formal research training but with much lived and professional experience. This Discussion Paper is but one legacy that Mark Champion leaves at CAEPR; our collaborations have been both fruitful and productive for both Mark and CAEPR and we hope that they continue. 


\section{Table of Contents}

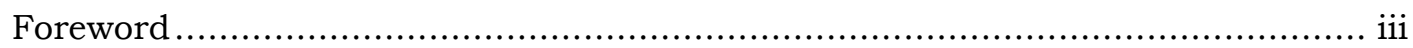

Abbreviations and acronyms .............................................................. vii

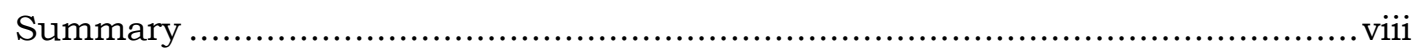

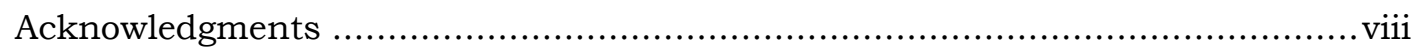

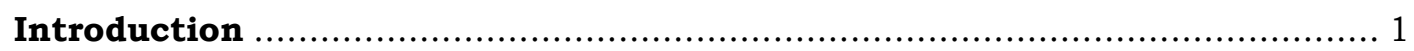

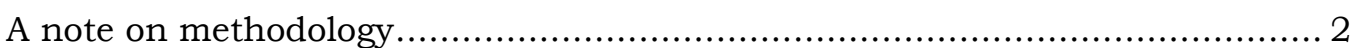

The Indigenous Employment Centre initiative …................................... 2

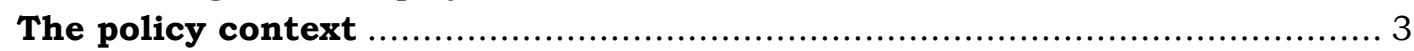

The Indigenous Employment Policy ....................................................... 3

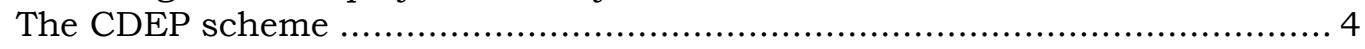

The IEC Work Preparation and Employment Trial ................................... 5

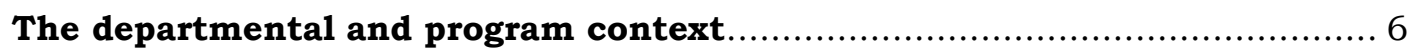

The Aboriginal and Torres Strait Islander Commission.............................. 6

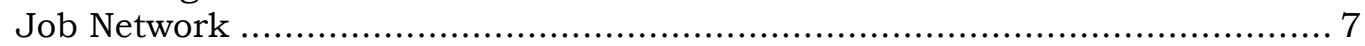

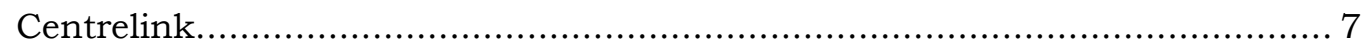

Job Search Trainer providers …........................................................ 8

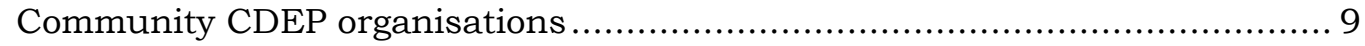

Indigenous Employment Centres: the urban CDEP context................... 9

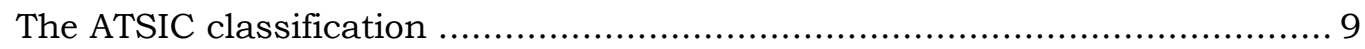

DEWR and Centrelink definitions …................................................. 10

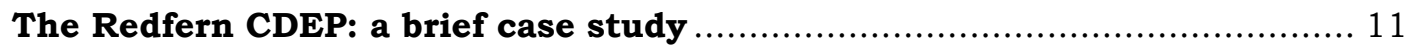

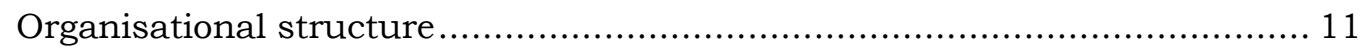

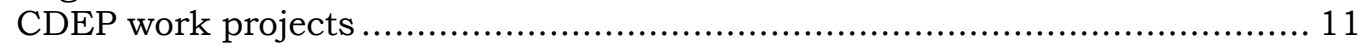

RAC employment policies and practice................................................. 11

The Redfern Aboriginal labour force and local labour market conditions ......... 12

The Redfern IEC trial ........................................................................... 13

The main challenges identified by RAC …............................................ 15

Conclusion: preliminary policy implications ......................................... 16

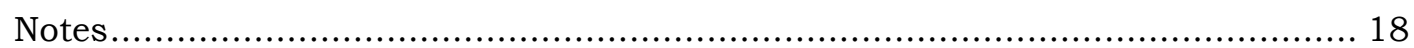

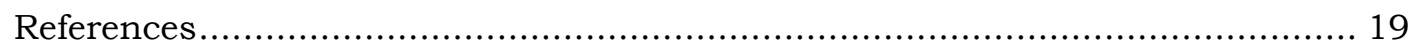

\section{Figures}

Fig. 1. The intra-organisational position of the IEC, and external linkages ......8

Fig. 2. Labour force status: Indigenous population (Redfern) and total population (South Sydney), 1991 and 1996. 


\section{Abbreviations and acronyms}

$\begin{array}{ll}\text { ABS } & \text { Australian Bureau of Statistics } \\ \text { ANU } & \text { The Australian National University } \\ \text { ATO } & \text { Australian Taxation Office } \\ \text { ATSIC } & \text { Aboriginal and Torres Strait Islander Commission } \\ \text { AWT } & \text { Australians Working Together } \\ \text { CAEPR } & \text { Centre for Aboriginal Economic Policy Research } \\ \text { CD } & \text { Collection District } \\ \text { CDEP } & \text { Community Development Employment Projects } \\ \text { CGC } & \text { Commonwealth Grants Commission } \\ \text { COA } & \text { Commonwealth of Australia } \\ \text { DEWR } & \text { Department of Employment and Workplace Relations } \\ \text { DEWRSB } & \text { Department of Employment, Workplace Relations and Small } \\ & \text { Business (now DEWR) } \\ \text { DFACS } & \text { Department of Family and Community Services } \\ \text { E/P ratio } & \text { employment to population ration } \\ \text { IEC } & \text { Indigenous Employment Centre } \\ \text { IEP } & \text { Indigenous Employment Policy } \\ \text { IT } & \text { information technology } \\ \text { JSCI } & \text { Job Seeker Classification Instrument } \\ \text { JST } & \text { Job Search Trainer } \\ \text { LFPR } & \text { labour force participation rate } \\ \text { MOU } & \text { Memorandum of Understanding } \\ \text { RAC } & \text { Redfern Aboriginal Corporation } \\ \text { SLA } & \text { Statistical Local Area } \\ \text { SOCOG } & \text { Sydney Organising Committee for the Olympic Games } \\ \text { SPRC } & \text { Social Policy Research Centre } \\ \text { TAFE } & \text { Technical and Further Education } \\ \text { UNSW } & \text { University of new South Wales } \\ \text { U rate } & \text { unemployment rate } \\ & \end{array}$




\section{Summary}

This paper explores the federal government's continued development of its Indigenous Employment Policy (IEP) with the launch of additional Indigenousspecific welfare reform initiatives flagged in the May 2001 Budget. One of these new initiatives focuses in particular on 'urban' Community Development Employment Projects (CDEP) schemes and policy initiatives aimed at encouraging them to take on the additional role of Indigenous Employment Centres (IECs).

The key function of IECs will be to move CDEP participants into mainstream employment. The paper presents a description of the policy background to this recent government initiative, and describes the proposed function and objectives of IECs.

The then Department of Employment, Workplace Relations and Small Business (DEWRSB) initiated a CDEP Work Preparation and Employment Trial, to test out the new initiative. The possible effects of the IEC initiative on CDEP organisations is examined through a preliminary study of Redfern CDEP in Sydney, which has agreed to participate in an IEC trial. Because the trial had only recently been implemented at the time the field visit was conducted by the author in 2001 , the paper is not a comprehensive evaluation of the Redfern trial. Rather, the Redfern case study provides an important preliminary ground-testing of the proposed objectives and implementation of IECs.

In conclusion the paper raises some preliminary practical and policy implications for the CDEP scheme in general, and for specific CDEP organisations that may be considering undertaking an IEC role.

\section{Acknowledgments}

I would like to thank Redfern Aboriginal Corporation in Sydney for their cooperation in the researching of this paper. In particular special thanks go to the Work Preparation and Employment Trial coordinators Trish Roughsedge and Allan Murray. I would also like to express my thanks and appreciation to the CDEP coordinator, Dennis Weatherall, the Chairperson of Redfern Aboriginal Corporation, Joan Quinlan, and to Bruce Loomes for their cooperation and support during the conduct of my fieldwork. I am also most grateful to those trial participants who participated in the interviews for this project.

In Canberra, I would like to thank Peter Armstrong, Rod Little (Regional Manager, ATSIC) and Jon Altman (Director, CAEPR), for facilitating the opportunity to undertake this research project. Thanks also to Jon for his ongoing support and valuable advice to me on numerous occasions and also to John Taylor, Boyd Hunter, Will Sanders and Bill Arthur for providing helpful comments on earlier drafts of this paper. I would also especially like to thank Diane Smith for her ongoing support throughout all stages of the writing of this paper. In general, I would like to thank all staff for their collegiate support and encouragement throughout my engagement with CAEPR. 
I must also express my thanks and appreciation for the support provided by the ATSIC National People and Development Section, particularly by Kathy Wright and Ray Gentle, as well as Ben Johnson, National Policy Office and Craig Leon and Jon Bok, National CDEP Section, Adelaide.

Thanks also to Linda Shaw, Kate Gumley and Mick Owen of DEWR for providing additional data, and to Frances Morphy for editing, Sally Ward for proofreading, and Wendy Forster for layout. 


\section{Introduction}

Two radical experiments have recently been undertaken in employment assistance in Australia. The first was the former Keating Labor government's Working Nation strategy which was subsequently dismantled and replaced by the current Coalition government's Job Network (Davidson 2001: 2, 4). A major component of both these government-sponsored employment assistance programs was to assist the long-term unemployed in particular, and there is much evidence to suggest that many unemployed Indigenous Australians fall into this category (Hunter 2000). Since the inception of Job Network there have been clear concerns raised about the effectiveness of its service delivery to Indigenous clients (Commonwealth Grants Commission (CGC) 2000). The Coalition government appears to have acknowledged these concerns with the launch of the Indigenous Employment Policy (IEP) at the beginning of the financial year 1999-2000. The IEP has restored, for Indigenous job seekers, a number of the features of Working Nation (Hunter \& Taylor 2001).

This paper will explore the federal government's continued development of its IEP with the launch of additional Indigenous-specific welfare reform initiatives flagged in the May 2001 Budget. One of these new initiatives focuses in particular on 'urban' CDEP schemes and related policy initiatives aimed at encouraging them to take on the additional role of Indigenous Employment Centres (IECs).

The key function of IECs will be to move Community Development Employment Projects (CDEP) participants-as well as Indigenous unemployed who are not employed on CDEP-into mainstream employment. The paper presents a description of the policy background to this recent government initiative, and describes the proposed function and objectives of IECs. In conclusion the paper raises some preliminary practical and policy implications for the CDEP scheme in general, and for specific CDEP organisations that may be considering undertaking an IEC role.

The possible effects of the new initiative on CDEP organisations will be examined through a preliminary study of one particular urban CDEP, Redfern CDEP in Sydney. The Redfern Aboriginal Corporation (RAC), the organisation that administers this CDEP scheme, has agreed to participate in an IEC trial. This CDEP Work Preparation and Employment Trial, to use the designated term, was initiated by the then Department of Employment, Workplace Relations and Small Business (DEWRSB 2001a), now the Department of Employment and Workplace Relations (DEWR). Because the trial had only recently been implemented at the time the field visit was conducted by the author in 2001, the paper is not a comprehensive evaluation of the Redfern trial. Rather, the Redfern case study provides an important preliminary ground-testing of the proposed objectives and implementation of IECs.

The paper will outline some preliminary questions and issues regarding the development over time of effective structures and policies within this CDEP organisation that are intended to facilitate the successful transition of 
participants into mainstream employment. In conclusion, the paper will consider what strategies (if any) may be required, at the level of urban CDEP organisations in general, and of the wider government policy, to ensure that effective outcomes will be achieved when the IEC program is fully implemented. The research will focus on investigating a series of preliminary questions:

1. What factors might be relevant in determining whether the Redfern CDEP organisation will be able to take on the additional role of an IEC?

2. What are the implications for the future implementation of the IEC program and its linkage to urban CDEP organisations?

3. What are the implications of the new urban CDEP policy for CDEP organisations in general, as they endeavour to deliver effective employment outcomes for both participants and government, and to balance cultural and welfare with employment objectives?

\section{A note on methodology}

The research presented in this paper is based upon primary data collected during a brief visit to RAC in August 2001. Views and commentary were sought from the chairperson of RAC, the trial coordinators, CDEP management and some participants. Additional secondary data were also collected from analysis of the 1991 and 1996 Censuses and DEWR and Aboriginal and Torres Strait Islander Commission (ATSIC) administrative data. During the course of the research, discussions were held with DEWR and ATSIC staff about the objectives of the IEC program and the trial. Because of confidentiality clauses attached to the trial contract, I was unable to access as much information as I would have liked from the RAC, although I was able to secure a copy of the trial contract template from DEWR at a later date.

\section{The Indigenous Employment Centre initiative}

On 22 May 2001 the federal Minister for Employment, Workplace Relations and Small Business, Tony Abbott, announced new funding in the 2001 Budget to assist Indigenous people to get long-term jobs. The Indigenous initiatives are a part of a larger package called Australians Working Together: Helping People to Move Forward (AWT) (Commonwealth of Australia (COA) 2001a). This funding package provides for:

1. Community Participation Agreements (remote area CDEPs only), which receive, via ATSIC, \$32.2 million over four years. The proposed implementation date was July 2001.

2. The establishment of up to 12 new Centrelink decentralised offices in remote communities, attracting $\$ 9.2$ million over four years. The proposed implementation date is September 2002.

3. Assistance for CDEPs to take on the role of IECs, amounting to $\$ 31$ million (plus $\$ 17$ million-see below). The IEC program is to be implemented from February 2002. 
4. Increased education and training assistance for Indigenous Australians, amounting to $\$ 10$ million.

According to the various media releases circulated by Minister Abbott, in areas where there are good job opportunities, CDEP organisations will be encouraged to take on the role of IECs. The IECs will supposedly assist up to 10,000 participants to make the transition from CDEP work experience into paid employment or other employment assistance, at an additional cost of $\$ 31$ million over four years (Abbott 2001). Analysis of the Minister's statement and additional comment from DEWR indicates that the IEC program is specifically designed to assist CDEP participants to become 'job ready' for paid employment. The government is not, however, committing to helping to create the 10,000 paid jobs needed for these participants.

Funding for IECs will be provided through DEWR. In addition to the $\$ 31$ million earmarked from the 2001 Budget, existing departmental program funding of $\$ 17$ million will also be redirected from the current IEP, making a total of $\$ 48$ million available for the new IEC program. By way of further policy justification, the Minister stated that 'CDEPs provide valuable work experience for more than 30,000 Indigenous Australians, but they do not provide satisfactory long-term alternatives for a job in cities and regional centres where there are good chances of getting employment' (Abbott 2001).

\section{The policy context}

\section{The Indigenous Employment Policy}

The IEP is a key new program function for DEWR's Indigenous Employment Branch. It was launched in mid 1999 and its primary aim is to generate sustainable employment opportunities for Indigenous people, particularly in the private sector (CGC 2001b: 358). The overall policy has three key components:

1. An Indigenous Employment Program, consisting of:

- Wage Assistance for placement employers

- Structured Training and Employment Projects

- a CDEP Placement Incentive

- the Corporate Leaders for Indigenous Employment Project, and

- the National Indigenous Cadetship Project;

2. the Indigenous Small Business Fund; and

3. the Job Network.

Historically, DEWR's IEP, and in particular the CDEP Placement Incentive, appear to have evolved from a number of possible sources. The new IEC program is an enhancement of the CDEP Placement Incentive, a key sub-component of DEWR's IEP. Through the CDEP Placement Incentive, CDEP organisations are entitled to a bonus of $\$ 2,200$ for each participant who exits into full-time nonCDEP employment. 


\section{The CDEP scheme}

The CDEP scheme is a major program function of ATSIC. It began in 1977 in remote regions, and from the late 1980s to early 1990s was expanded to include Aboriginal and Torres Strait Islander people living in rural and urban centres (Sanders 1993). The 1997 Spicer Review of the CDEP scheme recommended the formulation of a revised objective for CDEP, to focus more on assisting participants into full-time unsubsidised employment (Spicer 1997: 2, 28-9).

Assisting participants into mainstream employment was not one of the original objectives of the CDEP scheme. In 1977, remote communities had limited or nonexistent job opportunities and for many these circumstances still prevail. Accordingly, the objectives of CDEP at the time related mainly to nonemployment, 'community development' outcomes. However, since the emergence of more urbanised CDEP schemes in the late 1980s, the emphasis on 'community development' has gradually been diluted, some might even say replaced. Under the 1987 Aboriginal Employment Development Policy, and certainly since the 1997 Spicer Review, government has increasingly encouraged a shift in the focus of CDEP objectives to the facilitation of enterprise activities and to assisting individuals into full-time employment (Martin 2001: 33).

Research commissioned by ATSIC and authored by CAEPR researchers demonstrates the continued and projected high levels of Indigenous population growth and, using historical data, estimated shortfalls in jobs for this increased population (Taylor \& Hunter, 1998: 4-7). This research is another factor that may have influenced government to formulate its IEP.

A number of other factors have also contributed to the perceived need to enhance the CDEP Placement Incentive, in the period following July 1999. First, there appears to have been a low take-up rate of the CDEP Placement Incentive bonus by CDEP organisations since its inception. Second, the then Secretary of DEWR, Peter Shergold, was of the view that the efforts of CDEP schemes in supporting the progression of participants into mainstream employment had been an 'abysmal failure' (Shergold 2001: 70).

Further, Noel Pearson's comments on the impact of 'welfare poison' in Cape York communities and his recent initiatives for trialing a Family Income Management Strategy in the Cape have generated wider public policy debate on Indigenous welfare and economic development (Pearson 2000a, 2000b).

The government-commissioned McClure Report, Participation Support for a More Equitable Society (McClure 2000) promoted and encouraged a radical overhaul of Australia's social security system. There has been some argument that the Report gave inadequate coverage to Indigenous-specific welfare reform initiatives (see ATSIC 2000a, 2000b; Smith 2001: 8). However, it did recommend, in respect to Indigenous people, the trialing of innovations in service delivery and support for community employment initiatives, in consultation with communities (McClure 2000: Recommendation A10). Referring specifically to the introduction of an integrated participation support payment system, the Report also recommended 
that pilots be undertaken to test the merits of alternative approaches that address the costs of participation and the transition from income support reliance to paid employment (Recommendation C5).

High-level negotiations between ATSIC and DEWR, particularly between the former Employment Minister Peter Reith and the Chairperson of ATSIC, Geoff Clarke, were also a major factor influencing changes to government employment policy in the lead-up to the 2001 Budget. Anecdotal evidence also suggests that CDEP organisations themselves advanced the proposition that they be given the opportunity to provide comparable if not equivalent services to those currently provided by Job Network members, as well as access to outcome fees and payments commensurate with those payed to Job Network members.

These historical factors all had influence in creating a government imperative to generate improved employment outcomes for Indigenous Australians, and all contributed to the new IEC strategy announced in the May 2001 Budget initiative.

\section{The IEC Work Preparation and Employment Trial}

DEWR is currently conducting a pilot of the IEC initiative, referred to as the CDEP Work Preparation and Employment Trial, with eight participating CDEP organisations from around Australia in a mix of metropolitan and regional sites. ${ }^{1}$ The trial commenced in July 2001 and will run for 12 months. It requires each participating CDEP organisation to provide volunteer CDEP participants with work preparation training and assistance into employment; and to provide pre-placement and post-placement support to employees and employers. The overall project will be subject to an independent evaluation, coordinated by DEWR during the latter part of the contract and after its completion. The trial, and its evaluation, will inform the implementation of the new IEC initiative (Shergold 2001).

Those CDEP organisations contracted to participate in the trial were required to meet the following criteria:

- the CDEP must be located in a strong, diverse labour market;

- 5 per cent or more of the area's workforce must be Indigenous;

- there should be a culture within the CDEP which supports participants obtaining employment off CDEP; and

- the CDEP should have a good track record of assisting participants into mainstream job outcomes (CGC 2001b: 360).

CDEP organisations have been contracted to place between 20 and 25 participants in sustainable employment of at least six months' duration during the 12-month contract period. Under DEWR contract terms and conditions, trial participants are required to be:

- Aboriginal and/or Torres Strait Islander people; 
- selected from the sponsor CDEP organisation's current, active, paid participants; and

- suitable to participate in the trial (i.e. ready for work preparation training, prepared to register with Centrelink, and seeking employment).

Preliminary program guidelines state that if an IEC participant is not placed with a suitable employer within the 12-month contract period, he or she must go back onto the CDEP program. The sponsoring CDEP organisation will receive up to $\$ 6,600$ per participant in the trial. The local Job Network member working in partnership with the CDEP organisation will also receive payment for each CDEP participant successfully placed in mainstream employment. ${ }^{2}$ The trial contract requires each participating CDEP to employ a dedicated trial coordinator. Funding is provided by DEWR and the position must be selected against the agreed job description and selection criteria (pers. comm. DEWR). A national advisory committee, comprising a representative of each participating CDEP and representatives of DEWR and ATSIC, has been established to support and advise on the running of the trial. The committee is currently meeting on a quarterly basis.

Not all urban CDEP organisations may want to take on an additional role as an IEC. However, it is important to note that CDEP organisations that do not provide IEC services will still be able to access payments through the CDEP Placement Incentive, should they exit participants into full-time employment (pers. comm. DEWR).

\section{The departmental and program context}

As Fig. 1 (see p. 8) demonstrates, the IEC initiative brings together elements from a number of different programs, government departments and service providers, making it a potentially complex new program. At the government level DEWR will be the main program and funding agency responsible for implementation, while at the community level it will be individual CDEP organisations and Job Network members which will undertake key implementation roles. ATSIC will also have a role to play in overseeing the initiative.

\section{The Aboriginal and Torres Strait Islander Commission}

The IEC initiative was developed out of negotiations between ATSIC and DEWR. Although it is not participating in the implementation of IEC policy as significantly as other agencies, as long as ATSIC continues to administer the CDEP program it will have an important role to play if the IEC strategy is to succeed. ATSIC will also have a major role on the national advisory committee which has been established to support and advise on the running of the employment trial. 


\section{Job Network}

Job Network is a national network of around 200 private, community and government organisations (including a number of Indigenous Job Network members) which have been contracted by the federal government to deliver employment services to assist unemployed people. Job Network providers have been contracted by DEWR to provide five main services to assist job seekers. These are:

- Job Matching, consisting of Labour Exchange services which are available to most unemployed job seekers regardless of whether they are on income support;

- Job Search Training, which mainly consists of 15 consecutive days of training in job-search techniques, which may include interview techniques and presentation, course-based assistance and other strategies. These services are mainly for job seekers unemployed for between three and 12 months;

- Intensive Assistance, which gives individually tailored assistance to more disadvantaged job seekers. Services can be provided for up to 15 months, with negotiated extensions for a further six months if required;

- The New Enterprise Incentive Scheme, which is mainly business related including training, assessment of business plans, business advice and mentoring support; and

- Project Contracting (Harvest Labour Services) which ensures that fruit and vegetable growers have access to sufficient labour to harvest crops.

The Job Network program area is also expected to have a significant role in the implementation and delivery of the IEC program. IECs and Job Network members will be expected to develop a joint or shared working relationship on the ground, to canvass employer vacancies and refer suitable CDEP participants for placement within full-time employment (pers. comm. DEWR).

\section{Centrelink}

When an individual first applies to join a CDEP scheme organisation as a participant, the CDEP coordinator must register them with Centrelink to confirm their welfare status and eligibility, and provide them with a Customer Reference Number. Additionally, those CDEP participants who may in the future request assistance to exit into mainstream employment through their CDEP's IEC will be required to register with Centrelink a second time, as an unemployed job seeker, before they can access any IEC services. This is also the case for job seekers on income support within the broader community who can only access Job Network services such as Job Search Training and Intensive Assistance through Centrelink. Centrelink therefore acts as an entry point or gateway for Indigenous 
unemployed job seekers receiving income support, for individuals joining a CDEP scheme, and for CDEP participants who may wish to exit into non-CDEP employment. This suggests a paradoxical classification of new IEC participants, who can be regarded simultaneously as employed and unemployed.

Centrelink will assess IEC participants using a tool developed by DEWR to assist with its labour market programs. Known as the 'Job Seeker Classification Instrument' (JSCI; see DEWRSB 2001b), it is operated under service arrangements with Centrelink and is used to identify those job seekers most in need of intensive assistance. The purpose of the JSCI is to measure a job seeker's difficulty in getting a job. A JSCI score of 50+ activates the highest level of Centrelink assistance. It is likely that many urban CDEP participants would be assessed at a JSCI 50+ rating. This rating requires the provision of ongoing case management, personalised support, intensive supervision, and training (Smith 2001: 30).

Fig. 1. The intra-organisational position of the IEC, and external linkages

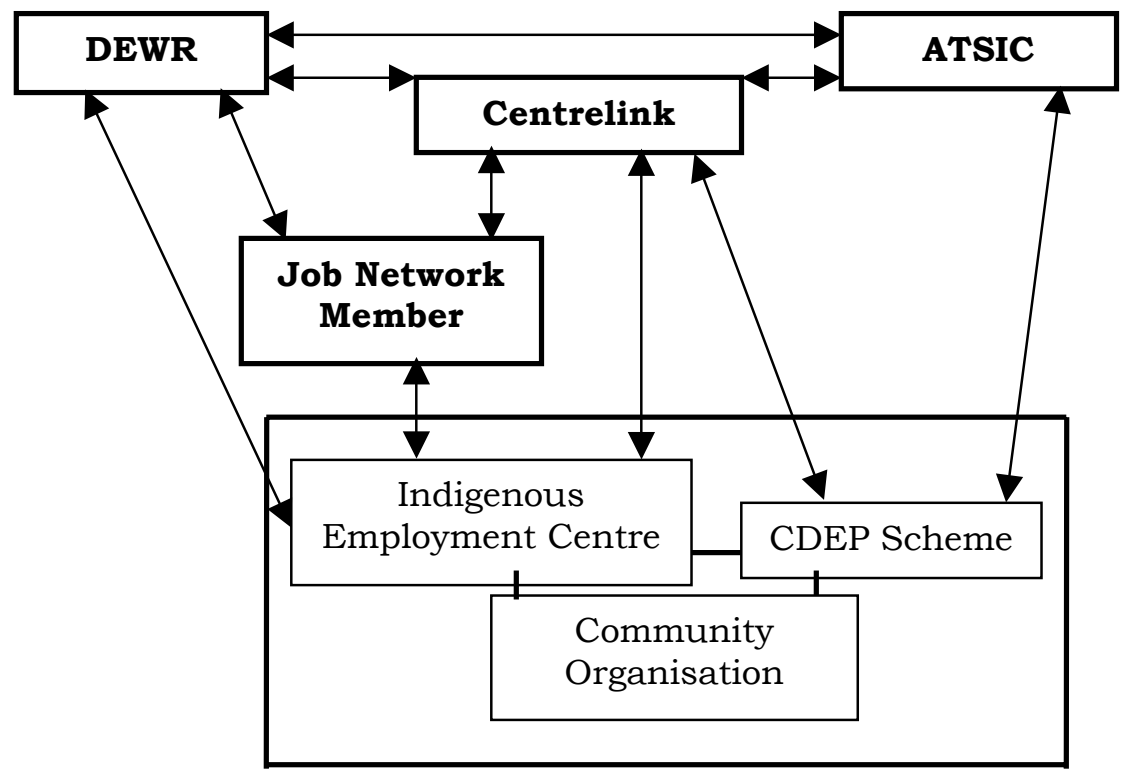

\section{Job Search Trainer providers}

Services delivered by Job Search Trainer (JST) providers will presumably also be crucial to the success of IECs. Should CDEP organisations feel they do not have the capacity to conduct pre-employment or work preparation training for their participants, they have the option of engaging a JST provider or other registered training organisation to provide the appropriate training on a fee-forservice basis. ${ }^{3}$ 


\section{Community CDEP organisations}

Community CDEP organisations based in urban areas will play the central role in the delivery of IEC outcomes. IECs will be 'grafted' onto CDEP schemes and together DEWR and ATSIC will fund them to fulfil both training and employment objectives.

It is envisaged that IECs will offer work experience, job search support and access to training, as well as providing support and mentoring assistance to Indigenous job seekers outside CDEP. IECs will also work with local employers and Job Network Members to find people sustainable employment (COA 2001b). As the departmental and program flowchart presented in Fig. 1 demonstrates, the provision of the range of support and services needed by each IEC presumes streamlined cooperation between a number of separate departments and their line programs. Much will depend on the effectiveness of that coordination.

\section{Indigenous Employment Centres: the urban CDEP context}

As at July 2001 there were approximately 269 CDEP organisations funded and supported by ATSIC, employing 35,406 participants. One-third of those are located in non-remote Australia. It is estimated that overall, the scheme employs 25 per cent of the Indigenous workforce (pers. comm. CDEP National Program Centre, ATSIC). The IEC initiative is specifically targeted at urban CDEP organisations.

The question of what constitutes an 'urban', as opposed to a 'remote' or 'rural', CDEP could be seen as a somewhat minor issue of administrative procedure. However, it is clearly becoming an increasingly important factor in the development of government policy and related objectives for Indigenous Australians. Since the agencies that will be responsible for delivering the IEC strategy will be DEWR and to a lesser extent ATSIC, it would seem appropriate to examine what 'urban/rural/remote' classification structures these departments are currently using for the purpose of administering government employment policy.

\section{The ATSIC classification}

ATSIC has determined that there are currently 102 'non-remote' CDEP schemes that employ a total of 13,314 participants, and 167 'remote' CDEP schemes that employ approximately 22,092 participants (pers. comm. ATSIC, July 2001). In other words approximately 30 per cent of all CDEP participants are now employed in non-remote locations. ATSIC uses the Australian Taxation Office (ATO) definition to distinguish non-remote from remote CDEPs. ${ }^{4}$ It uses this definition because of Department of Finance regulations governing the differing wage rates for CDEP participants employed in remote and non-remote regions. Note however that CDEP schemes may operate in a city or town which may be located in a remote region of Australia, (in accordance with ATO tax zone rules), but still have a vibrant labour market attached to it, for example Broome, Alice Springs and 
Darwin. In the context of the IEC policy, ATSIC's definition would appear to draw a superfluous distinction, given that the new policy seeks to improve unsubsidised employment outcomes for Indigenous people. However, there appears to be a growing trend to 'stream' CDEP policy and initiatives into two sets-one for urban CDEPs and another for CDEP schemes located in remote regions. CDEPs located in rural areas fall into an ambiguous zone between these two streams.

\section{DEWR and Centrelink definitions}

Factors taken into consideration by DEWR in inviting CDEPs to apply to participate in the employment trial included local Indigenous workforce population data and the prevalence of strong local labour market conditions. ${ }^{5}$ It would seem that Australian Bureau of Statistics (ABS) census data would provide the most accurate source of information for determining applicability under these criteria, as some remote and rural Indigenous communities also have strong labour market conditions attached, and this emerges clearly from the census data. However, while census data would give a more refined view of local labour market conditions and Indigenous workforce population figures, it is collected only once every five years.

DEWR has therefore developed a number of additional tools to assist with its ongoing measurement of labour market conditions. One such tool, presented in Small Area Labour Markets (DEWRSB 2001c) gives estimates of regional labour market data disaggregated at two levels:

- Employment-related data are estimated for the 19 DEWR Labour Market Regions established for the purposes of tendering out employment services under Job Network; ${ }^{6}$ and

- labour market developments are presented at the Statistical Local Area (SLA) level, the smallest available ABS geographical unit, on a State or Territory and metropolitan-non-metropolitan basis. Labour market data are presented at this level using a combination of both Centrelink data and monthly labour force statistics.

Another tool developed by DEWR to assist with its labour market programs is the JSCI (DEWRSB 2001b). However, in the context of attempts to improve unsubsidised employment outcomes for Indigenous people, other than assessing possible structural barriers to employment for participants, the JSCI in its present form appears superfluous to the objectives of the new IEC policy. It needs to be radically overhauled to develop greater cultural relevance in its application. ${ }^{7}$

In summary, the factors used by DEWR to establish what would constitute a strong, diverse labour market (as emphasised in the IEC criteria) are not tailormade for the IEC initiative. It would appear that the eight CDEPs chosen to participate in the current trial were selected through a collaborative effort between DEWR and ATSIC. Policy clarification will be needed as to what constitutes an 'urban' CDEP scheme, as the IEC program moves beyond the trial 
stage to its more extensive application. Clarification will also be required on whether a strict urban classification is actually suitable for the objectives of the new program.

\section{The Redfern CDEP: a brief case study}

\section{Organisational structure}

The Redfern CDEP scheme is located in the suburb of Redfern, Sydney and lies within the ABS SLA of South Sydney. The CDEP scheme is coordinated by the Redfern Aboriginal Corporation (RAC), an organisation incorporated under the Aboriginal Councils and Associations Act. The scheme began in 1991 with 35 participants and increased to 100 participants in the 2000-01 financial year.

RAC is managed by a board of nine Indigenous directors. At the management level, the organisation's staffing structure includes a CDEP coordinator and an assistant coordinator who organise the work programs, supervise the participants and assume an administrative role within the RAC office. Employed under these coordinators are three additional supervisors who act as leading hands for specific work projects, and a manager of the organisation's local construction company.

\section{CDEP work projects}

Redfern CDEP has developed a number of income-generating enterprises including:

- a house construction company;

- a contract to produce Treaty merchandise such as T-shirts and bags;

- the sale of Indigenous cultural products at major airports; and

- Harbour Dreaming Cultural Cruises (see Loomes 2001)

RAC also has a number of community development work projects and small-scale activities including screen-printing and sewing, furniture removals, garbage removal and a lawn-mowing business. During the lead-up to the Sydney Olympics in 2000, Redfern CDEP was also contracted by SOCOG to carry out major landscaping works at various Olympic venues including Olympic Park, the equestrian area, the Olympic Shooting Range and the Olympic regatta site.

\section{RAC employment policies and practice}

RAC has progressively developed policies and procedures particularly relating to expected behaviour and codes of conduct. Participants work up to 18 hours per week. A skills assessment is carried out with each prospective participant in order to determine their previous work experience, level of numeracy and literacy, and work interests. It will be interesting to see if, in future, RAC and indeed other CDEP organisations also adopt some aspects of Centrelink's JSCI. 


\section{The Redfern Aboriginal labour force and local labour market conditions}

Analysis of data taken from the 1991 and 1996 Censuses gives an overall indication of the changing employment conditions for the South Sydney SLA where the Redfern CDEP scheme is located. ${ }^{8}$ It should be noted that there has always been a high rate of mobility in Redfern's Aboriginal population, resulting in a high and continual turnover of the organisation's CDEP participants (see Loomes 2001: 225; Smith 1995: 11). CDEP participants may also live outside Redfern in neighbouring suburbs such as Marrickville and Alexandria and even as far away as the outer west. However, the majority of participants live in Redfern itself, particularly on the 'Block', and ABS data taken from the 1991 and 1996 Censuses therefore gives a good indication of the level of Indigenous engagement with the wider employment market.

In 1991 the total population of South Sydney SLA was 65,455. In 1996 this had risen to 69,018 persons. In 1991 the Indigenous population of Redfern totalled 491 persons. In 1996 this number had increased to 812 persons.

Fig. 2. Labour force status: Indigenous population (Redfern) and total population (South Sydney), 1991 and 1996

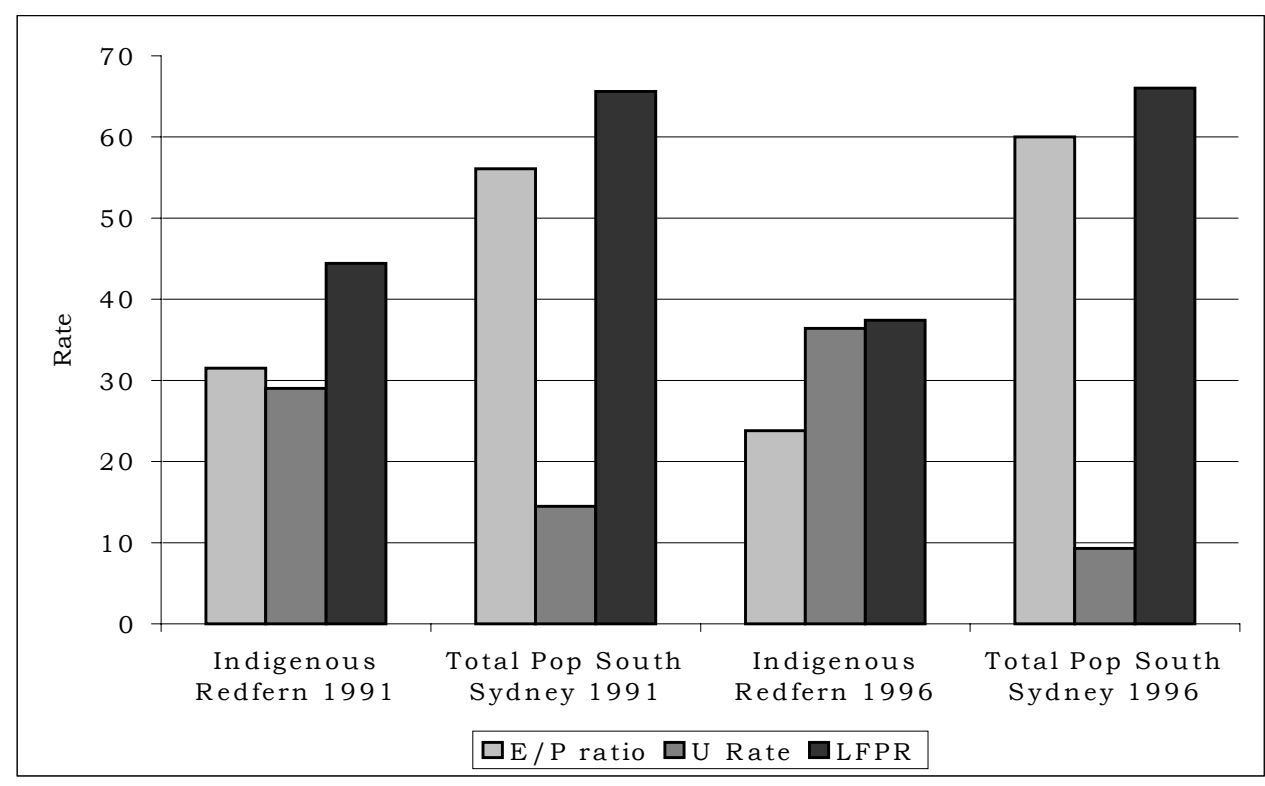

Fig. 2 sets out the labour force status of the Indigenous population of Redfern in comparison to the total population in South Sydney. Data indicate that during the years 1991-96 the employment rate (E/P ratio) had increased overall for the total population of South Sydney. During the same period the unemployment rate (U rate) for South Sydney's total population had decreased, while the labour force participation rate (LFPR) had remained steady. However, over the same period, 
the Indigenous unemployment rate for Redfern had risen while both the employment rate and labour force participation had fallen. In other words, as Smith (1995) earlier suggested, high unemployment rates in Redfern reflect the presence of an 'enclave' which is seemingly cut off from engagement in the wider local mainstream economy, and has few historical networks into local businesses.

\section{The Redfern IEC trial}

It is within this labour market context that the Redfern CDEP has been contracted to participate in the IEC trial for a 12-month period, to place up to 29 participants in sustainable employment of at least 6 months' duration. Redfern CDEP is one of four CDEPs based within the Sydney metropolitan area and is the only one that volunteered to participate in the trial.

The RAC stated that it decided to become involved in this pilot for a number of reasons, including that:

- it was given the opportunity to submit a proposal to participate;

- the directors and management felt that it was important that a CDEP organisation based in Sydney should participate in this trial;

- the RAC felt there could be incentives for training opportunities for participants leading to improved employability; and

- that the trial provided the opportunity for the CDEP organisation to employ an additional coordinator to administer the pilot program.

It was also suggested by RAC that in the past many CDEP organisations (including RAC) were not claiming for payments they were entitled to from DEWR for placing participants into mainstream employment. Two possible contributing factors were that the CDEP placement program had only recently been implemented and that CDEP organisations were not aware of its details. This trial could help ensure that participating CDEPs would be made more aware of their entitlements, and would collect them accordingly. RAC trusts that, by participating in this trial, CDEP participants will be given the opportunity of exposure to the mainstream labour market and will hopefully achieve longer-term exits into full-time employment. However, the organisation also sees the increased self-esteem and confidence of individuals participating in the trial as an important achievement in itself.

The RAC has engaged and employed two individuals who job-share the duties of the trial coordinator. Both are Indigenous. Although the author was not given access to the contract terms and conditions between RAC and DEWRSB, the trial coordinators advised that they are similar to conditions imposed on Job Network providers. The contract does stipulate measured milestones that are intended to encourage full-time unsubsidised employment outcomes for the individuals participating. The contract also specifies that the CDEP organisation should provide follow-up support to participants chosen for the trial through an action plan that the coordinators supervise and monitor regularly. 
Over the course of the case study it was possible to interview only two participants from the Redfern trial. One was still currently with their placement employer, the other had returned to CDEP employment. A request was made to interview additional participants taking part in the trial, but the trial coordinators felt that this might cause stress and disruption for participants, who were still in the process of settling into their placements. The following information about the trial participants was, however, provided by RAC:

- 29 CDEP participants elected to take part in the trial, which commenced on 9 July 2001;

- of these participants, 16 are in the 16-24 age group, while the remaining 13 are 25 or over;

- there are ten males in the 16-24 age group and four who are 25 or over;

- there are six females in the 16-24 age group and nine who are 25 or over;

- there are nine participants who have been placed with employers within the South Sydney SLA; and

- there are 20 participants who are currently placed under the trial with employers outside the South Sydney SLA.

Participants have been placed with a broad range of employers across the public, community and private sectors, including local pre-schools, Aboriginal organisations and major international hotel chains. However, again the coordinators felt it would be unfair to provide information on each specific placement employer as RAC was still in the process of establishing a professional working relationship with them.

According to the RAC trial coordinators, funding provided by DEWR for administrative and management support is sufficient, although because of a confidentiality clause, dollar amounts could not be specified. The coordinators also stated that DEWR personnel had provided guidance and support for the trial.

Included within the trial budget is a training component. The RAC has also been able to secure a Memorandum of Understanding (MOU) with a local JST provider to support their trial. The MOU includes work preparation training workshops for participants in resumé building, Internet access, and so on. Training requirements varied between individuals, with some requiring more preparation than others. In addition to work preparation training, the JST provider has donated computers, IT support, printers, ergonomic chairs and computer tables to RAC.

Pre-placement and post-placement support given to the participating employee mainly involves mentoring support provided on a one-on-one basis by the CDEP trial coordinators. Pre-placement and post-placement support given to employers has been initially financial, consisting of a Centrelink wage assistance subsidy. However, a mentoring role may also be developing, since the trial coordinator will become a crucial contact point for the employer should any difficulties arise with a placement. 
ATSIC is providing assistance to the trial in the form of the CDEP wage subsidy for participants until they are placed with a suitable employer. The trial coordinators highlighted one major concern relating to the CDEP grant terms and conditions. Under ATSIC rules, if participants stop turning up for work, they can remain on the CDEP schedule for no longer than five weeks before they must be removed. Thus a participant who is having difficulties at their new place of employment only has a five-week window before they must decide if they wish to return to the CDEP or not. The trial coordinators felt that this was not enough time for participants to 'settle in' and to determine if their new work environment was likely to be welcoming and acceptable.

Trial incentives provided by RAC include additional payments made to placement participants from any milestone payments received by RAC from DEWR. Other assistance given to trial participants includes train fares, clothing allowance, driver's licence fees, birth certificate extract fees, administration expenses, and Internet access (particularly to job web sites such Koorie Connections). Additional support provided by RAC to participants also included interview coaching and travel by CDEP vehicle, but only in cases of emergency.

\section{The main challenges identified by RAC}

The trial coordinators identified nine possible challenges and problems that might impact on the organisation's ability to achieve the required employment trial outcomes. These were:

1. the likely need for substantial ongoing mentoring and case management support for participants outside the parameters of the agreed timeframes;

2. the need to build effective linkages with Job Network providers;

3. evidence of racism among the non-Indigenous staff of one of the placement employers (in this particular instance a trial participant overheard a nonIndigenous work colleague utter the comment 'I hate Aboriginal people, they make me sick');

4. that most participants within RAC require intensive assistance to become job ready;

5. that pre-vocational training programs in addition to Job Search Training appears to be a 'put off' factor amongst trial participants; that is, there can be an over-emphasis on long periods of preliminary training which can lead to participants becoming 'training fatigued', resulting in discouragement and, in some cases, an unwillingness to continue in the program;

6. that participants have high expectations of gaining employment after completion of Job Search Training; if employment does not materialise, they may experience real discouragement;

7. that contract milestones need to be realistic, and synchronised with the operating functions of trainer providers such as TAFE;

8. that non-Indigenous placement employers need to foster positive ways to induct participants into the workplace. There was one instance where a participant was not given the formal on-the-job training that was necessary for them to perform their work functions properly. It was left up to another 
work colleague, who had no training qualifications other than on-the-job experience, to assist the participant. IEC funding should perhaps include 'cross-cultural awareness training' and on-the-job training components;

9. that currently, work preparation training processes do not allow the detection of a participant's potential disability, such as a substance misuse problem. RAC was concerned about the possibility of an employer backlash and the reinforcement of negative stereotypes, should participants taking part in the trial display a poor and careless work ethic, due to a dependency on alcohol or drugs.

\section{Conclusion: preliminary policy implications}

The welfare reform initiatives discussed here have developed out of the federal government's belief that Australia's social security system and labour market programs needed reviewing and re-orientation (Newman 1999b). The key reason given for policy reform was the existence of and increase in 'welfare dependency' created by a 'passive' welfare system (Newman 1999a). On the face of it, those individuals participating in CDEP schemes are not included within the pejorative term 'welfare dependency'. There is, however, an apparently increasing government effort to characterise those CDEP schemes based in or near a strong labour market, as a 'stepping stone' out of work-for-welfare into full-time employment (Shergold 2001: 71). Redfern CDEP itself developed out of the aspirations of a group of young Indigenous people who, as a youth action group, attempted to confront and address pressing social, economic and other problems which had become the daily experiences of the Aboriginal residents of Redfern (Smith 1995: 7).

The RAC has negotiated with DEWR to take on the role of an IEC and, in the broader context, to test the workability of the government's new welfare reform agenda. However, it is not clear what this will mean for Redfern CDEP itself and what the wider implications are for other urban CDEP organisations, and for refining the policy framework for this new initiative.

CDEPs wishing to take on the role of IECs will need to consider carefully the impact on their own enterprises; in particular, whether the possible movement of reasonably skilled people to employment outside the scheme's enterprisegenerating activities will be deleterious for their own enterprises. There are limited numbers of experienced, highly skilled participants in CDEP organisations, and any particular CDEP organisation will need to consider whether any income earned from successful placements will compensate for the loss of reasonably skilled personnel to outside employment.

Another option for a CDEP could be to generate income from trial placements within the organisation's own enterprise activities-were this to be allowed under the DEWR guidelines. The benefits would be twofold: the organisation would retain reasonably skilled personnel, while also receiving income for job placement. This would of course be subject to the priorities and wishes of workers 
participating in the trial. The disadvantages would be that participants would still be subsidised by CDEP wages, unless the enterprises undertook to pay full wages out of any profits and not from CDEP funds. Alternatively, 'urban' CDEPs could be allowed to apply for the Centrelink wage subsidy.

The capacity of government to ensure that the necessary coordination is achieved between the various departments and agencies with key program policy roles will be a critical factor, and will need to be carefully considered. For example, at the bureaucratic level DEWR, ATSIC and Centrelink will need to fully coordinate and evaluate the IEC program. DEWR has confirmed that an evaluation of the trial, following the first six months of its operation, was to take place sometime in January or February 2002.

At the community level, a CDEP organisation with an IEC and its Job Network counterpart will need to cooperate fully to ensure that Indigenous clients receive maximum assistance and advantage. The assumption is that this will be a positive working relationship. It is not at all clear whether this will be the case, or whether there is a national strategy to facilitate such partnerships.

This policy initiative also raises important questions about the capacity of CDEPs to take on a major new workload that will require considerable expertise and skills to implement. A related challenge is whether CDEP organisations will be able to secure the funding that will be required to achieve realistic outcomes in realistic timeframes. The CGC has already highlighted concerns with respect to the effectiveness of Job Network service arrangements for Indigenous people (CGC 2001a: 351). The expectation is that IECs will assist Job Network members to increase the success rate in placing Indigenous job seekers into full-time employment. This will need to be monitored carefully and should be part of any evaluation of the IEC trial. It will be important to make the final evaluation of the trial publicly and widely available so that all CDEP organisations can be better informed of potential opportunities and challenges they might face.

It should also be noted that more than two-thirds of urban CDEP participants are located in non-metropolitan urban CDEPs or regional CDEPs. ${ }^{9}$ The workload for regional CDEPs may be greatly increased because of low employment growth in these areas, and the possible requirement for longer-term intensive assistance for IEC participants. Low employment growth also increases the possibility of a high failure rate in placing IEC participants into full-time employment, and may result in excessive recycling through the CDEP and IEC programs in these locations, thereby repeating a well-documented labour force 'syndrome' amongst Indigenous Australians. This reinforces once again the importance of defining the proper criteria for what would constitute an 'urban' CDEP scheme.

Another major challenge will be the recognition and management of social and cultural factors. CDEP participants will need to become aware of, and accept, the workplace conditions operating in the general labour market, particularly in the private sector. For many participants, a job placement outside CDEP will be the first time they are exposed to competitive market workplace conditions. Although some private sector corporations and companies may need to temporarily adjust

CENTRE FOR ABORIGINAL ECONOMIC POLICY RESEARCH 
and reorganise management workplace practices to ease Indigenous people into full-time employment (particularly with regards to social and cultural factors), IEC participants will need to accept that any workplace restructuring undertaken for their benefit can only be for the short term.

The existing literature on the CDEP scheme suggests that long-term CDEP employment fosters and cultivates flexible workplace behavioural patterns. This particular 'industrial relations culture' (Rowse 2001: 44) is often characterised as a positive component of community management and a reflection of culturallybased work patterns. However, that very flexibility could prove to be at odds with and possibly unacceptable within the confines of the mainstream economy, and may hinder the transition into sustained employment out of CDEP. Certainly, exposure to mainstream labour market conditions presents both opportunities and challenges for participants experiencing full-time employment for the first time outside CDEP. As Tim Rowse recently commented, 'CDEP is an infringement on the privilege of private investors to define the conditions of material well being through the market place. It throws into question the power of the market to define the nature and intensity of work' (2001: 44). There may well be opposing tensions between CDEP employment and mainstream employment. The transition into IEC sponsored 'work' in the mainstream economy suggests CDEP organisations will now have two types of 'work'. One will be CDEP defined work, the other will be general labour market defined work.

These comments are made at a time when the IEC trial is still under way. They therefore raise preliminary issues for consideration during the remainder of the trial and and for assisting in the refinement of IEC guidelines and objectives for a later full implementation phase. Certainly, it is already clear that a number of important issues and questions are coming to light during the trial.

However, as the chairperson of RAC remarked, 'one of the main reasons why we wanted to participate in this trial was to give our people another option, another choice. If they want to continue to work on CDEP then they can, but if they want to get a job outside, we want to help them achieve that too.' As long as RAC continues to manage and maintain control over any CDEP wages entitlements, and to have discretion about what is to be defined as 'work' to receive those wages entitlements, then CDEP participants will continue to enjoy this choice.

\section{Notes}

1. The eight CDEPs participating in the trial pilot are located in Brisbane, Port Augusta, Shepparton, Canberra-Queanbeyan, Broome, Geraldton, Sydney and Newcastle.

2. Job Network members are paid at varying rates for their placement, depending on the nature of the labour market in the region. Generally the more difficult the environment for the creation of job opportunities, the more is paid for successful placements. According to government estimates the minimum price for Intensive Assistance totals $\$ 4,663$ for funding level $\mathrm{A}$, and $\$ 9,219$ for funding level $\mathrm{B}$. However, tenders were required to include an explanation if they believed their individual 
circumstances required them to submit prices siginificantly higher than the government's estimated price effects for the broader industry sector. The generally accepted figure is between $\$ 7,000$ and $\$ 11,000$, with $\$ 11,000$ applying in the areas with the most difficult labour markets. Most Job Network members are not likely to disclose their payment structures (they are commercial-in-confidence) (DEWR Employment Services Request for Tender 1999 and pers. comm. ATSIC).

3. Many Job Network Members are also JST providers, and CDEP organisations may access training services delivered via their local Job Network member.

4. According to the ATO Taxation Ruling TR 94/28 Income tax: List of points in isolated areas for zone rebate purposes, s. 79A of the Income Tax Assessment Act 1936 provides for a rebate in recognition of uncongenial climatic conditions, isolation and the high cost of living encountered by residents of those areas in comparison with the rest of Australia.' The zones incorporate most of the continent excluding eastern Queensland below Mackay, eastern New South Wales, all of Victoria, the southern part of South Australia, and south west Western Australia.

5. Five per cent or more of an area's workforce must be Indigenous (CGC 2001a: 360).

6. DEWR has revised arrangements for the second tender process for the delivery of employment services to unemployed people across Australia for the three years from 28 February 2000 to 2 March 2003. Australia has been divided into 19 tendering regions, which will be further divided into just under 140 employment services areas, to assist the processes for referral of job seekers to Job Network members by Centrelink and to help tenderers construct their bids. This aims to promote an improvement in employment services in regional, rural and remote Australia with tenderers being able to bid the 'real cost' of providing services in these areas (DEWRSB 1999).

7. Operated under service arrangements with Centrelink, the JSCI is used to identify those job seekers most in need of intensive assistance. For Aboriginal and Torres Strait Islanders, the JSCI only factors into account a variable referred to as the 'small community social dynamic', which recognises an additional disadvantage for Indigenous people who do not reside in the major population centres of Sydney, Melbourne, Brisbane, Perth, Adelaide, Newcastle, the Gold Coast, Canberra, Hobart, Wollongong and Townsville.

8. Data used are from estimates of 1991 and 1996 ABS Census of Population and Housing taken from South Sydney SLA and Redfern Collection District (CD). Note that the area covered by the 1996 Redfern CD incorporates two 1991 CDs-Waterloo and Redfern.

9. These are areas with a population between 1,000 and 99,999 people. According to the CGC's Report on Indigenous Funding, ATSIC CDEP participants by Section of State for the 1999-2000 financial year were employed as follows: Metropolitan CDEPs 3.9\%, Regional CDEPs 39.3\%, Remote CDEPs 56.8\% (CGC 2001b: 258).

\section{References}

Abbott, T. 2001. 'More jobs for Indigenous Australians', A statement by T. Abbott MP, DFACS, Canberra.

Aboriginal and Torres Strait Islander Commission (ATSIC) 2000a. 'Response to Participation Support for a More Equitable Society', ATSIC submission to the McClure Welfare Reform Reference Group, ATSIC, Canberra. 
ATSIC 2000b. 'Social welfare reform', ATSIC submission to the McClure Welfare Reform Reference Group, January 2000, ATSIC, Canberra.

Commonwealth of Australia (COA) 2001a. Australians Working Together: Helping People to Move Forward (AWT), A statement by Senator the Hon Amanda Vanstone and the Hon Tony Abbott MP, May 2001, COA, Canberra. [http://www.together.gov.au]

- 2001b. 'Support for CDEP participants to get a job', AWT Factsheet No. 22, COA, Canberra. [http://www.together.gov.au/GovernmentStatement/FactSheets/FS22.asp]

Commonwealth Grants Commission (CGC) 2000. 'Draft report on the Indigenous Funding Inquiry', Discussion Paper IFI 2000/2, CGC, Canberra.

- 2001a. Report on Indigenous Funding, COA, Canberra.

- 2001b. Report on Indigenous Funding, Supporting Material, Indigenous-Specific Employment Programs, COA, Canberra.

Davidson, P. 2001. 'Employment assistance for long-term unemployed people: Time for a re-think', Paper presented to the Social Policy Conference, July 2001, SPRC, UNSW, Sydney.

Department of Employment, Workplace Relations and Small Business (DEWRSB) 1999. 'Fact sheet: Job Network-second round tender arrangements', DEWRSB, Canberra. [http:/ /www.dewrsb.gov.au/department/budget/1999/factsheets/tender_jn.htm]

- 2001a. CDEP Work Preparation and Employment Trial Summary, Indigenous Employment Branch, DEWRSB, Canberra.

- 2001b. Job Seeker Classification Instrument (JSCI), DEWRSB, Canberra.

_ 2001c. Small Area Labour Markets, Australia, DEWRSB, Canberra.

Hunter, B. 2000. 'Social exclusion, social capital, and Indigenous Australians: Measuring the social costs of unemployment', CAEPR Discussion Paper No. 204, CAEPR, ANU, Canberra.

— and Taylor, J. 2001. 'Indigenous jobs growth and unemployment, 1996-2006: The impact of CDEP', Australian Journal of Labour Economics, 4 (2): 65-76.

Loomes, B. 2001. 'Using the system to our advantage: Redfern Corporation CDEP, Sydney', in F. Morphy and W. Sanders (eds), The Indigenous Welfare Economy and the CDEP Scheme, CAEPR Research Monograph No. 20, CAEPR, ANU, Canberra.

McClure, P. 2000. Participation Support for a More Equitable Society: Final Report of the Reference Group on Welfare Reform, DFACS, Canberra.

Martin. D. 2001. 'Community development in the context of welfare dependence', in F. Morphy and W. Sanders (eds), The Indigenous Welfare Economy and the CDEP Scheme, CAEPR Research Monograph No. 20, CAEPR, ANU, Canberra.

Newman, J. 1999a. 'The challenge of welfare dependency in the 21st century', Discussion Paper prepared for the Welfare Reform Reference Group, DFACS, Canberra.

- (1999b) 'The future of welfare in the 21st century', Speech given at the National Press Club, 29 September, Canberra.

Pearson, N. 2000a. 'Misguided policies a toxic cocktail', The Australian, 24 October.

- 2000b. Our Right to Take Responsibility, Noel Pearson and Associates, Cairns. 
Rowse. T. 2001. 'The political dimensions of community development', in F. Morphy and W. Sanders (eds), The Indigenous Welfare Economy and the CDEP Scheme, CAEPR Research Monograph No. 20, CAEPR, ANU, Canberra.

Sanders. W. 1993, "The rise and rise of the CDEP scheme: An Aboriginal "workfare" program in times of persistent unemployment', CAEPR Discussion Paper No. 54, CAEPR, ANU, Canberra.

Shergold, P, 2001. 'The Indigenous Employment Policy: A preliminary evaluation', in F. Morphy and W. Sanders (eds), The Indigenous Welfare Economy and the CDEP Scheme, CAEPR Research Monograph No. 20, CAEPR, ANU, Canberra.

Smith. D. 1995. 'Redfern works: The policy and community challenges of an urban CDEP scheme', CAEPR Discussion Paper No. 99, CAEPR, ANU, Canberra.

- 2001. 'Community Participation Agreements: A model for welfare reform from community-based research', CAEPR Discussion Paper No. 223, CAEPR, ANU, Canberra.

Spicer, I. 1997. Independent Review of the Community Development Employment Projects (CDEP) Scheme, Expenditure Review Committee, COA, Canberra.

Taylor, J. and Hunter, B. 1998. The Job Still Ahead: Economic Costs of Continuing Indigenous Employment Disparity, ATSIC, Canberra. 


\section{Centre for Aboriginal Economic Policy Research Publications}

For information on earlier CAEPR Discussion Papers and Research Monographs please contact:

Publication Sale, Centre for Aboriginal Economic Policy Research, The Australian National University, Canberra, ACT, 0200, Telephone: 02-6125 8211, Facsimile: 02-6125 2789. Information on CAEPR, abstracts or summaries of all CAEPR print publications and those published electronically, can be found at the following WWW address: http://online.anu.edu.au/caepr/

\section{MONOGRAPH SERIES}

5. The Relative Economic Status of Indigenous Australians, 1986-91, J. Taylor, 1993.

6. Regional Change in the Economic Status of Indigenous Australians, 1986-91, J. Taylor, 1993.

7. Mabo and Native Title: Origins and Institutional Implications, W. Sanders (ed.), 1994.

8. The Housing Need of Indigenous Australians, 1991, R. Jones, 1994.

9. Indigenous Australians in the Economy: Abstracts of Research, 1993-94, L.M. Roach and H.J. Bek, 1995.

10. Native Title: Emerging Issues for Research, Policy and Practice, J. Finlayson and D.E. Smith (eds), 1995.

11. The 1994 National Aboriginal and Torres Strait Islander Survey: Findings and Future Prospects, J.C. Altman and J. Taylor (eds), 1996.

12. Fighting Over Country: Anthropological Perspectives, D.E. Smith and J.D. Finlayson (eds), 1997.

13. Connections in Native Title: Genealogies, Kinship and Groups, J.D. Finlayson, B. Rigsby and H.J. Bek (eds), 1999.

14. Land Rights at Risk? Evaluations of the Reeves Report, J.C. Altman, F. Morphy and T. Rowse (eds), 1999.

15. Unemployment Payments, the Activity Test and Indigenous Australians: Understanding Breach Rates, W. Sanders, 1999.

16. Why Only One in Three? The Complex Reasons for Low Indigenous School Retention, R.G. Schwab, 1999.

17. Indigenous Families and the Welfare System: Two Community Case Studies, D.E. Smith (ed.), 1999.

18. Ngukurr at the Millennium: A Baseline Profile for Social Impact Planning in South East Arnhem Land, J. Taylor, J. Bern and K.A. Senior, 2000.

19. Aboriginal Nutrition and the Nyirranggulung Health Strategy in Jawoyn Country, J. Taylor and N. Westbury, 2000.

20. The Indigenous Welfare Economy and the CDEP Scheme, F. Morphy and W. Sanders (eds), 2001. 


\section{RECENT DISCUSSION PAPER SERIES}

204/2000 Social exclusion, social capital, and Indigenous Australians: Measuring the social costs of unemployment, B.H. Hunter.

205/2000 Job-searching and careers: Young Torres Strait Islanders, 1999, W.S. Arthur and J. David-Petero.

206/2000 Career aspirations and orientation to work: Young Torres Strait Islanders, 1999, W.S. Arthur and J. David-Petero.

207/2000 Education, training and careers: Young Torres Strait Islanders, 1999, W.S. Arthur and J. David-Petero.

208/2000 A case study of the Bungala CDEP: Economic and social impacts, M.C. Gray and E. Thacker.

209/2000 The CDEP in town and country Arnhem Land: Bawinanga Aboriginal Corporation, J.C. Altman and V. Johnson.

210/2000 'If it wasn't for CDEP': A case study of Worn Gundidj CDEP, Victoria, R. Madden.

211/2001 Anangu population dynamics and future growth in Uluru-Kata Tjuta National Park, J. Taylor.

212/2001 Indigenous Australians and the rules of the social security system: Universalism, appropriateness and justice, W. Sanders.

213/2001 Is welfare dependency 'welfare poison'? An assessment of Noel Pearson's proposals for Aboriginal welfare reform, D.F. Martin.

214/2001 Indigenous data from the ABS Labour Force Survey: What can they tell us? J. Taylor and B.H. Hunter.

215/2001 Autonomy rights in Torres Strait: From whom, for whom, for or over what? W.G. Sanders and W.S. Arthur.

216/2001 Indigenous families and the welfare system: The Kuranda community case study, Stage Two, R. Henry and A. Daly.

217/2001 Indigenous families and the welfare system: The Yuendumu community case study, Stage Two, Y. Musharbash.

218/2001 Giving credit where it's due: The delivery of banking and financial services to Indigenous Australians in rural and remote areas, S. McDonnell and N. Westbury.

219/2001 Implications of developments in telecommunications for Indigenous people in remote and rural Australia, A. Daly.

220/2001 Indigenous autonomy in Australia: Some concepts, issues and examples, W.S. Arthur.

221/2001 Indigenous land in Australia: A quantitative assessment of Indigenous landholdings in 2000, D.P. Pollack.

222/2001 Valuing native title: Aboriginal, statutory and policy discourses about compensation, D.E. Smith. 
223/2001 Community Participation Agreements: A model from community-based research, D.E. Smith.

224/2001 A regional CDEP for four remote communities? Papunya, Ikuntji, Watiyawanu and Walungurru, W. Sanders.

225/2001 Building Indigenous learning communities, R.G. Schwab and D. Sutherland.

226/2001 Sustainable development options on Aboriginal land: The hybrid economy in the twenty-first century, J.C. Altman.

227/2002 The Indigenous population of Cape York peninsula, 2001-2016, J. Taylor and M. Bell.

228/2002 Urban CDEPs as Indigenous Employment Centres: Policy and community implications, M. Champion.

\section{WORKING PAPER SERIES}

Available at no cost on WWW at http://online.anu.edu.au/caepr/

1/1999 Three nations, not one: Indigenous and other Australian poverty, B.H. Hunter.

2/1999 Further investigations into Indigenous labour supply: What discourages discouraged workers? B.H. Hunter and M.C. Gray.

3/1999 Dealing with alcohol in Alice Springs: An assessment of policy options and recommendations for action, M. Brady and D.F. Martin.

4/1999 Aboriginal people in the Kakadu region: Social indicators for impact assessment, J. Taylor.

5/1999 Reforming the Northern Territory Land Rights Act's financial framework into a more logical and more workable model, J.C. Altman and D.P. Pollack.

6/2000 Governance and service delivery for remote Aboriginal communities in the Northern Territory: Challenges and opportunities, N. Westbury and W. Sanders.

7/2000 What's in it for Koories? Barwon Darling Alliance Credit Union and the delivery of financial and banking services in north-west New South Wales, N. Westbury.

8/2000 The relative social and economic status of Indigenous people in Bourke, Brewarrina and Walgett, K. Ross and J. Taylor.

9/2001 Indigenous communities and business: Three perspectives, 1998-2000, J.C. Altman

10/2001 Indigenous Australian arrest rates: Economic and social factors underlying the incidence and number of arrests, B.H. Hunter

11/2001 Sensitivity of Australian income distributions to choice of equivalence scale: Exploring some parameters of Indigenous incomes, B.H. Hunter, S. Kennedy, and D. Smith 
